\title{
Formulation of Vegetable Soup Mixture Using Physically Modified Sweet Potato Starch as a Thickener
}

\author{
Senanayake SA ${ }^{1 *}$, Ranaweera KKDS ${ }^{1}$, Gunaratne $A^{2}$ and Bamunuarachchi $A^{1}$ \\ ${ }^{1}$ Department of Food Science and Technology, Faculty of Applied Sciences, University of Sri Jayewardenepura, Gangodawila, Nugegoda, Sri Lanka \\ ${ }^{2}$ Department of Agriculture, University of Sabaragamuwa, Belihuloya, Sri Lanka
}

\begin{abstract}
Potential application of modified sweet potato starch as a substitute thickener for corn starch was studied using native starches extracted from five different cultivars of commonly available cultivars in Sri Lanka. Physicochemical properties (SP, WSI, pasting, gelatinization) and digestibility of native and modified (heat - moisture treated, $30 \%$ moisture, $85^{\circ} \mathrm{C}$ for 6 hrs) starches were analysed. Modified Swp3 (Wariyapola white), Swp4 (Pallepola)and Swp5 (Malaysian) starches were selected based on the favourable condition exhibited in the required physical and chemical properties and applied in the vegetable soup formula and tested against corn starch added samples for viscosity difference and sensory attributes.

Viscosity of the reconstituted soup powder and sensory analysis showed that Swp4 and Swp5 had significantly high leve $(p<0.05)$ and the average rank for mouth feel (taste), texture and overall acceptability was significantly high $(p<0.05)$ in Swp5 added samples. Shelf life studies ensured 6 months stability with negligible level of moisture increase and total plate count in air tight polypropylene packages at ambient temperatures $\left(28-31^{\circ} \mathrm{C}\right)$. Results of this study revealed a possibility of applying physically modified Swp4 and Swp5 starches as a substituent food ingredient for corn starch to improve the thickness of food products.
\end{abstract}

Keywords: Modified starch; Physicochemical properties; Sweet potato starch; Thickener

\section{Introduction}

The sweet potato (Ipomea batatas (L) Lam) is a tuberous - rooted perennial plant belonging to the Convolvulaceae or morning glory family and, the main commercial producers of sweet potatoes are China, Indonesia, Vietnam, Japan, India and Uganda [1]. Sweet potato is a traditional crop in Sri Lanka and grown mainly in the wet and intermediate zones and nearly about 50,000 tones are produced annually. All of this production is used for human consumption since high consumer preference for roots prevents the utilization of it as an animal feed since the production is insufficient [2]. Sweet potato is mainly consumed by low income people since it is one of the cheap substitutes for starchy staples such as rice, wheat and potatoes [3] and contains a considerable level of starch, soluble sugars, vitamins, minerals and other nutrients.

Sweet potato starch is being used worldwide in various food and industrial applications [4]. Native starches have limitations which reduce their use at industrial level due to the inability to tolerate a wide range of processing techniques, distribution and storage conditions. Modified starches are superior to native starches due to their improved functional properties and widely employed in processed foods in recent years. In Sri Lanka for food industrial application corn starch is being used mostly as a thickening agent. The country's expenditure in importing this food ingredient is considerably high. In the year 2011 the country has imported about 8, 794, $286 \mathrm{~kg}$ for US\$ 4, 881, 855. Possible use of modified sweet potato starch as a thickening and viscosity enhancer was studied using five different cultivars commonly available in Sri Lanka. Physicochemical properties and digestibility percentage were considered based on our previous studies of the same cultivars [5] in potential application in the soup mix when selecting the suitable modified starch and viscosity change and sensory attributes were considered in preparation of the vegetable soup formula.

\section{Materials and Methods}

Matured tubers of sweet potatoes namely, Swp1 (Wariyapola red),
Swp 3 (Wariyapola white), Swp 4 (Pallepola variety), Swp 5 (Malaysian variety) and Swp 7 (CARI 273) were randomly collected from Dhambulla, Horana and Gokarella areas in Sri Lanka and prepared for analysis two to three days after harvesting.

\section{Starch separation}

Starch separation was carried out according to the method described by Senanayake et al., (2013) [2]. Fresh tubers were washed, peeled and diced. Dipped in ice water containing $100 \mathrm{ppm}$ sodium metabisulphite to minimize browning and was wet milled at high speed in a laboratory scale blender with 1:2 w/v of tap water for 1 minute and filtered through a gauze cloth. Residue was repeatedly wet milled and filtered thrice and suspension was kept overnight for settling of starch The supernatant was decanted and the settled residue was further purified with repeated suspension in tap water $(1: 2 \mathrm{v} / \mathrm{v})$ followed by the settling for 24 hours. The purified starch was dried at $35^{\circ} \mathrm{C}$, sifted through $300 \mu \mathrm{m}$ sieve, sealed and packed for analysis.

Swelling power (SP), water soluble index (WSI), pasting properties and gelatinization

SP, WSI, pasting properties and gelatinization enthalpy were determined by methods described by Senanayake et al. [5]. Starch $(100$ $\mathrm{mg}, \mathrm{db}$ ) was weighed directly into a screw - cap test tube, and $10 \mathrm{ml}$ distilled water was added. The capped tubes were placed on a vortex

*Corresponding author: Senanayake SA, Department of Food Science and Technology, Faculty of Applied Sciences, University of Sri Jayewardenepura Gangodawila, Nugegoda, Sri Lanka, Tel: +94 11 2802914; E mail: surajisena@gmail.com

Received February 25, 2014; Accepted March 24, 2014; Published April 03, 2014

Citation: Senanayake SA, Ranaweera KKDS, Gunaratne A, Bamunuarachchi A (2014) Formulation of Vegetable Soup Mixture Using Physically Modified Sweet Potato Starch as a Thickener. J Food Process Technol 5: 313. doi:10.4172/21577110.1000313

Copyright: (C) 2014 Senanayake SA, et al. This is an open-access article distributed under the terms of the Creative Commons Attribution License, which permits unrestricted use, distribution, and reproduction in any medium, provided the original author and source are credited. 
mixer for 10 seconds and incubated at $85^{\circ} \mathrm{C}$ water bath for 30 minutes with frequent mixing. The tubes were cooled to room temperature in an iced water bath and centrifuged at $2000 \mathrm{Xg}$ for 30 minutes, the supernatant was removed and remaining sediment in the tube was weighed $\left(\mathrm{W}_{\mathrm{s}}\right)$. The supernatant was dried to constant weight $\left(\mathrm{W}_{1}\right)$ in a drying oven at $100^{\circ} \mathrm{C}$. The water swelling power was calculated as follows:

$$
\mathrm{SP}=\mathrm{W}_{\mathrm{s}} /[0.1 \mathrm{X}(100 \%-\mathrm{WSI})](\mathrm{g} / \mathrm{g})
$$

Where WSI $=\mathrm{W}_{1} / 0.1 \mathrm{X} 100 \%$

Thermograms were obtained using a TA 2920 Modulated DSC Thermal Analyzer Differential Scanning Calorimeter (DSC) equipped with a thermal analysis data station (TA Instruments, Newcastle, DE). Starch (3 mg) was weighed onto the aluminum DSC pan and distilled water $(9 \mu \mathrm{l})$ was added with a micro syringe. Pans were sealed and allowed to stand for 1 hour at room temperature. The scanning temperature range and heating rate were $30-140^{\circ} \mathrm{C}$ and $10^{\circ} \mathrm{C} / \mathrm{min}$, respectively, using an empty pan as reference.

Pasting properties of starches were determined in duplicate replications using a Rapid Visco - Analyzer (RVA) model 3D (Newport Scientific, Warriiewood, Australia). Flour (3.5 g, 14\% moisture basis) was mixed with distilled water $(25 \mathrm{~g})$ in the canister and loaded using STD2 heating and cooling profile.

\section{Digestibility level}

Starch digestibility was measured by the method described by Zhang et al. (2002) [4]. A sample of $500 \mathrm{mg}$ was placed in a weighed centrifuge tube (Tarsons, $50 \mathrm{ml})$ with addition of $15 \mathrm{ml}$ phosphate buffer $(0.15 \mathrm{M}$, $\mathrm{pH}$ 6.5), $30 \mathrm{mg} \mathrm{CaCl}, 30 \mathrm{mg}$ gelatin and $30 \mathrm{mg}$ pancreatin (Sigma Co., St. Louis, MO). The capped tubes were placed in a shaking water bath at $37^{\circ} \mathrm{C}$ with a sufficient speed to keep the flour in suspension for $12 \mathrm{hrs}$ and stopped the reaction with $5 \mathrm{ml}$ of $1 \% \mathrm{H}_{2} \mathrm{SO}_{4}$. The suspension was centrifuged at $20,000 \mathrm{~g}$ for 10 minutes and the supernatant was decanted and the residue pellet was dispersed with $15 \mathrm{ml}$ of $80 \%$ ethanol and re centrifuged for 5 minutes. The supernatant was decanted and the tubes with the residue pellet were dried at $50^{\circ} \mathrm{C}$ for $6 \mathrm{hrs}$, then at $80^{\circ} \mathrm{C}$ to constant weight, cooled and weighed. Starch digestibility was expressed as percent weight loss after digestion. A blank without pancreatin was included for each sample to adjust the results.

\section{Heat - Moisture Treatment (HMT) of the extracted starch}

Previous studies of the same cultivars showed more effective SP and WSI from HMT with $20 \%$ moisture at $85^{\circ} \mathrm{C}$. Therefore, HMT at this level was employed. From the extracted starch $20 \mathrm{~g}$ of each sample was taken and adjusted the moisture levels to $20 \%$ and placed the moisture adjusted samples in tubes with a sealing cap and equilibrated at room temperature for 24 hours. Samples were heated at $85^{\circ} \mathrm{C}$ for 6 hours. Occasional shaking was done to samples within the treatment period for homogeneous distribution of moisture. After treatment, the samples were cooled to room temperature and dried at $40^{\circ} \mathrm{C}$ to a uniform moisture level of $10 \%$ and equilibrated at room temperature for 2 days.

\section{Formulation of vegetable soup mixture and viscosity analysis}

A vegetable soup mixture was formulated with steamed and dehydrated dhal (40\%), carrot powder (25\%), Leeks (14\%), tomatoes (3\%), salt (2.5\%), modified starch (2\%), white pepper (1.5\%), garlic (1\%), cinnamon and curry leaves $(0.5 \%$ each). Approximately $5.5 \mathrm{~g}$ of powder was reconstituted with $100 \mathrm{~mL}$ of boiling water, and simmered for 5 minutes. Cooled and the viscosity was measured at $35^{\circ} \mathrm{C}$ by using a viscometer (Brookfield RVT, 206480, USA).

\section{Sensory analysis of soup mixture}

Heat moisture treated Swp3, Swp4, Swp5 and corn starch as the control, added soup mixtures were reconstituted and given sample codes as 227, 257, 217 and 242 respectively. Five point unipolar hedonic scale using 30 numbers of untrained panels to measure the sensory properties of appearance, colour, aroma, texture (thickness), and taste (mouth feel) and overall acceptability to find the best application of the modified starch.

\section{Shelf life analysis of dehydrated soup mixture}

Total viable cell count was carried out using the pour plate method up to 6 months at one month intervals. Nutrient agar was used for enumeration of bacteria. Random sample of $1 \mathrm{~g}$ was serially diluted with sterile distilled water up to $10^{-6}$. One $\mathrm{ml}$ aliquot from a $10^{-2}$ to $10^{-5}$ was transferred aseptically into sterile petri dishes. Added about $15 \mathrm{ml}$ of sterile melted and cooled nutrient agar into each petri dish. The inoculum was evenly mixed with media by rotating the plates and allowed to solidify. The inverted plate was incubated at $37^{\circ} \mathrm{C}$ for 48 hours in an incubator. The total viable count was determined using a colony counter. Moisture content of the soup mixture packed in polypropylene packages at room temperature was monitored in each month using the moisture balance (SHIMDZU, MOC63u) for 6 months.

\section{Statistical analysis}

MINITAB (ver 14) package was used for data analysis. Analysis of variance (ANOVA) with Tukey's Family error range test was performed to examine the differences in viscosity and shelf life study of the formulated soup mixture. Samples in triplicate were used and a significance level of $p \leq 0.05$ was applied. Sensory evaluation of formulated vegetable soup mix was carried out using Kruskal-Wallies non parametric ANOVA method with five point unipolar hedonic scale.

\section{Results and Discussion}

\section{Physicochemical properties}

By considering the SP, WSI for HMT starch and gelatinization enthalpy, peak viscosity(PV) obtained from RVA of native starch, HMT Swp3, Swp4 and Swp5 starches were added as the thickening agent and corn starch added sample was kept as the control. Previous studies done by us showed that SP of HMT starches ranged between 8.5-12.5 g/g [1]. Digestibility level of native starch was significantly higher $(\mathrm{p}<0.05)$ except for Swp3 and Swp4 of, in the native starch. $\mathrm{PV}$ and gelatinization enthalpy are significantly higher in the native form and lower digestibility is shown in HMT Swp7 cultivar (Table 1). Different levels of HMT on some varieties of sweet potato starches can lead to functionality variations and increased gelatinization temperature, pasting stability, decreased peak viscosity, swelling power and solubility [4]. However our results show increased values with HMT treatment.

\section{Viscosity difference in reconstituted starch}

Heat - moisture treatment at $85^{\circ} \mathrm{C}$ and $20 \%$ has increased the viscosity of native starches except for Swp 3 cultivar. High temperature has altered the crystalline structure of starch granules and increased the ability to make hydrogen bonds with water molecules. As a result 


\begin{tabular}{|c|c|c|c|c|c|}
\hline Sample & ${ }^{A} S P(g / g)$ & BWSI (\%) & ${ }^{c} P V(R V U)$ & $\begin{array}{c}\text { DGelatinization } \\
\Delta \mathrm{H}(\mathrm{j} / \mathrm{g})\end{array}$ & $\begin{array}{c}\text { Digestibility } \\
\text { (\%) }\end{array}$ \\
\hline Swp1 & $7.9 \pm 0.1^{c}$ & $1.6 \pm 0.1^{\mathrm{e}}$ & $222 \pm 4.5^{\mathrm{b}}$ & $15.7 \pm 0.4^{\mathrm{b}}$ & $21.7 \pm 0.7^{b}$ \\
\hline Swp3 & $8.7 \pm 0.2^{c}$ & $1.8 \pm 0.1^{\mathrm{e}}$ & $225 \pm 2.1^{b}$ & $6.4 \pm 0.7^{b}$ & $21.9 \pm 1.5^{b}$ \\
\hline Swp4 & $8.7 \pm C$ & $1.3 \pm 0.1^{f}$ & $257 \pm 4.2^{\mathrm{a}}$ & $4.3 \pm 0.3^{c}$ & $3.5 \pm 0.9^{b}$ \\
\hline Swp5 & $8.0 \pm 0.1^{c}$ & $2.1 \pm 0.1^{d}$ & $248 \pm 3.2^{\mathrm{a}}$ & $13.0 \pm 0.4^{\mathrm{d}}$ & $23.5 \pm 0.4^{b}$ \\
\hline Swp7 & $5.8 \pm 0.1^{d}$ & $.1^{9}$ & $14 \pm 4.1^{\circ}$ & $0.1 \pm 0.5^{\mathrm{a}}$ & $0.3^{c}$ \\
\hline *Swp1 & $11.5 \pm 1.2^{b}$ & $3.9 \pm 0.2^{\mathrm{a}}$ & ndt & ndt & $13.2 \pm 0.3^{d}$ \\
\hline *Swp3 & $12.0 \pm 0.9^{a}$ & $3.2 \pm 0.3^{b}$ & ndt & ndt & $23.5 \pm 0.9^{b}$ \\
\hline *Swp4 & $12.5 \pm 0.8^{a}$ & $4.2 \pm 0.3^{\mathrm{a}}$ & ndt & ndt & $26.6 \pm 0.7^{a}$ \\
\hline *Swp5 & $12.1 \pm 0.2^{\mathrm{a}}$ & $4.1 \pm 0.3^{a}$ & ndt & ndt & $19.5 \pm 0.5^{c}$ \\
\hline *Swp7 & $8.5 \pm 0.7^{c}$ & $2.8 \pm 0.3^{c}$ & ndt & ndt & $13.7 \pm 0.2^{\mathrm{d}}$ \\
\hline
\end{tabular}

A,B Source (Senanayake et al., 2013, ISRN Agronomy), C,DSource (Senanayake et al., 2013, Tropical Agriculture, Trinidad), *HMT starch, ndt - not determined, Values are means of triplicate determinations \pm standard deviation, values denoted by different superscripts in each column are significantly different at $p<0.05$.

Table 1: Physicochemical properties of sweet potato starches.

increased moisture level with altered crystalline structure has increased the SP and WSI of the HMT starch. High level moisture above the gelatinization temperature has increased the granular swelling thus enhancing the level of viscosity. Granular rearrangement due to heat - moisture treatment has reduced the viscosity in the Swp3 added sample.

There is no significant difference $(\mathrm{p}<0.05)$ in the viscosity of the soup mixture with added native starches of Swp5, Swp7 and HMT Swp1 type. Combination of other ingredients in the soup mixture has increased the viscosity of the Swp7 added mix although the swelling power and WSI are low compare to other starches. Figure 1 shows the viscosity difference in each soup mixture prepared with modified starches of five cultivars.Studies done on different verities of corn starch showed swelling power ranged between $13.7-20.7 \mathrm{~g} / \mathrm{g}$, gelatinization enthalpies of $11.2-12.7$ and viscosity ranging from $804-1252 \mathrm{cP}$ [6]. Our results show a $\Delta \mathrm{H}$ value ranging from $15.7-20.1$ (Table 1) for sweet potatoes which is higher than for the corn starch. HMT treated starch along with the other ingredients in the soup mix has increased the total viscosity of the soup mixes in a marked way compare to the commonly used corn starch which shows the potential application of HMT sweet potato starch as a viscosity enhancer.

\section{Sensory analysis of the soup mixture}

Sensory studies showed that all four samples were significantly different in appearance, colour, texture, aroma and overall acceptability while there was no significant difference in taste $(\mathrm{p}<0.05)$ in samples with Swp3 and Swp5. Table 2 gives the average rank obtained for each attribute of the tested samples. Average ranks for aroma, taste, texture, appearance and overall acceptability was significantly high for formulas prepared with both Swp5 and Swp4 HMT starches while Swp5 had the highest level of overall acceptability. Corn starch added sample ranked in the colour preference attribute only (Table 2). Thickness given by the added sweet potato starch is significantly higher than the corn starch. Our results show that modified HMT added samples are more superior to corn starch in sensory aspects except for the colour attribute. Therefore modified starches (Swp3, Swp4 and Swp5) can be successfully substituted to corn starch as a thickener with higher level of sensory acceptability.

\section{Analysis of the shelf life}

Moisture content and colony forming units in $1 \mathrm{~g}$ of the dry mix were significantly lower $(\mathrm{p}<0.05)$ in polypropylene for the period of 6 months at ambient temperature. Shelf life studies show a significantly low level $(\mathrm{p}<0.05)$ of moisture increase in all the samples during the 6 month time period. Maximum moisture level present in wheat flour is $14 \%$ (SLS, 1980). Moisture percentage after 6 months' time was also less than $14 \%$ in all the samples and this shows that these samples can be kept for a further period if the temperature and humidity control measures were taken (Figure 2). Initial level of microorganisms in all tested samples were comparatively lower in all samples slightly increase after the fourth month in Swp3 and Swp4 samples (Table 3).

This slight increase in the cfu may be due to the favourable increase of moisture $\%$ within the environment after the fourth month. Although the increase of moisture took place, low water activity has restricted the growth rate of microorganisms. Results show a positive correlation of the cfu and moisture content and initial level of microbial load may also be a reason to have a comparatively high level of microbes in Swp3 sample compare to other two samples. According to New Zealand standards maximum level of aerobic plate count is $10^{6} \mathrm{cfu} / \mathrm{g}$ at $35^{\circ} \mathrm{C}$ for dry soup powders. The number of the $\mathrm{cfu} / \mathrm{g}$ we observed for all three samples were much lower compare to the maximum allowable

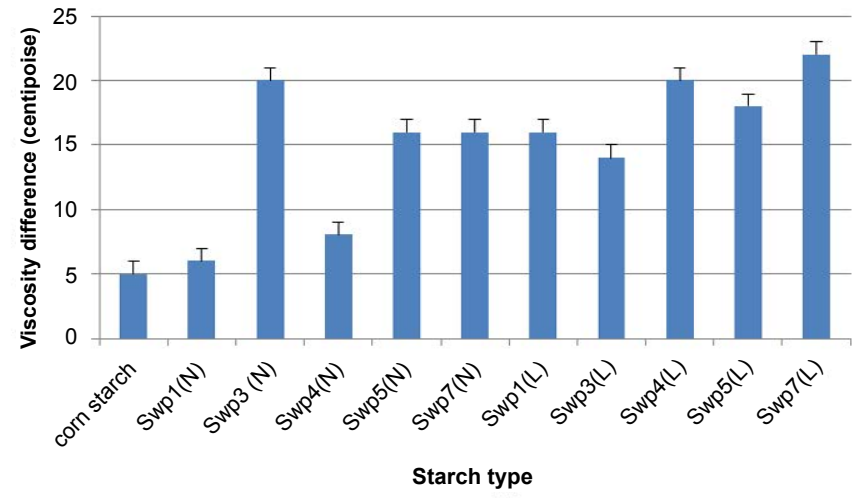

${ }^{\text {b }} \mathrm{Swp}(\mathrm{L})-\mathrm{HMT}$ at $85^{\circ} \mathrm{C}$ and $20 \%$ moisture level for $6 \mathrm{hrs}$.

Figure 1: Viscosity change due to added starch. aSwp $(\mathrm{N})$ - native starch.

\begin{tabular}{|l|c|c|c|c|c|c|}
\hline Treatment & Appearance & Colour & $\begin{array}{c}\text { Texture } \\
\text { (thickness) }\end{array}$ & $\begin{array}{c}\text { Taste } \\
\text { (mouth } \\
\text { feel) }\end{array}$ & Aroma & $\begin{array}{c}\text { Overall } \\
\text { acceptability }\end{array}$ \\
\hline 227 (Swp3) & 50.8 & 54.5 & 59.7 & 56.4 & 54.8 & 48.4 \\
\hline 257 (Swp4) & 69.7 & 56.5 & 68.4 & 74.4 & 65.5 & 80.9 \\
\hline 217 (Swp5) & 79.2 & 63.5 & 72.2 & 64.7 & 71.1 & 69.2 \\
\hline 242( control) & 42.3 & 67.4 & 41.8 & 46.6 & 53.7 & 53.7 \\
\hline
\end{tabular}

$\mathrm{N}=30$ number of untrained male and female panelists between the ages of $20-30$ yrs.

Table 2: Average ranks of sensory attributes charts of sensory analysis for the developed formulas of soup mixtures.

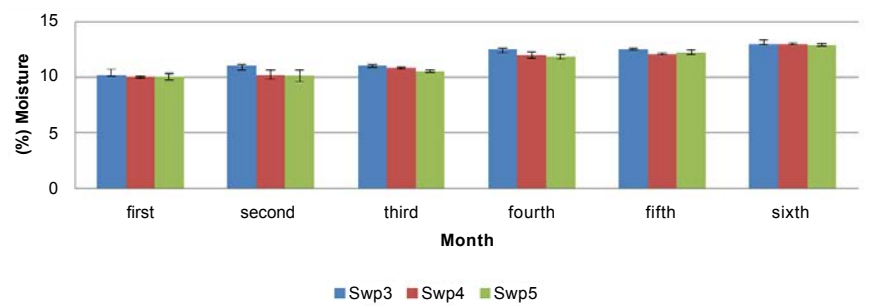

Standard deviation is given by vertical bars

Figure 2: Level of moisture in packed mixture for 6 months period. 
Citation: Senanayake SA, Ranaweera KKDS, Gunaratne A, Bamunuarachchi A (2014) Formulation of Vegetable Soup Mixture Using Physically Modified Sweet Potato Starch as a Thickener. J Food Process Technol 5: 313. doi:10.4172/2157-7110.1000313

\begin{tabular}{|c|c|c|c|c|c|c|c|}
\hline Sample & $\begin{array}{c}\text { Initial } \\
\text { level }\end{array}$ & $\begin{array}{c}\mathbf{1}^{\text {st }} \\
\text { month }\end{array}$ & $\begin{array}{c}\mathbf{2}^{\text {nd }} \\
\text { month }\end{array}$ & $\begin{array}{c}\mathbf{3}^{\text {rd }} \\
\text { month }\end{array}$ & $\begin{array}{c}4^{\text {th }} \\
\text { month }\end{array}$ & $\begin{array}{c}\mathbf{5}^{\text {th }} \\
\text { month }\end{array}$ & $\begin{array}{c}\mathbf{6}^{\text {th }} \\
\text { month }\end{array}$ \\
\hline Swp3 & 2 & 2 & 2 & 5 & $7 \times 10^{1}$ & $3 \times 10^{2}$ & $2 \times 10^{3}$ \\
\hline Swp4 & 0 & 0 & 2 & 5 & $1 \times 10^{1}$ & $2 \times 10^{1}$ & 35 \\
\hline Swp5 & 0 & 0 & 2 & 2 & 2 & 7 & 15 \\
\hline
\end{tabular}

Samples were triplicated and average cfu/g (colony forming units per gram) was taken.

Table 3: Total plate count (cfu/g) within 6 month period.

level. Therefore the microbial safety of the product can be assured for a further period of time.

\section{Conclusion}

Our study reveals a potential application of physically modified sweet potato starch as a thickener for a food mixture which shows superior quality from corn starch. All three types of tested starches showed significant level of thickening when in the soup mixture. Swp4 and Swp 5 cultivars ranked high in sensory attributes of appearance, taste, aroma and overall acceptability. Dry soup powder had 6 month shelf life and can be successfully substituted to corn starch as a food additive in viscosity enhancement.

\section{References}

1. Senanayake SA, Ranaweera KKDS, Gunaratne A, Bamunuarachchi A (2013) Comparative Analysis of Nutritional Quality of Five Different Cultivars of Sweet Potatoes (Ipomea batatas (L) Lam) in Sri Lanka. Food science \& nutrition 4 : 284-291.

2. Senanayake SA, Ranaweera KKDS, Gunaratne A, Bamunuarachchi A (2013) Physico chemical properties of five cultivars of sweet potato (Ipomea batatas (L) Lam) roots grown in Sri Lanka. Tropical Agriculture (Trinidad) 90: 96-110.

3. De Silva KPU, Jayawardene SDC (1989) Indigenous and recent advances in sweet potato production, processing and marketing in Sri Lanka.

4. Zhang ZCC, Wheatley, Corke $H$ (2002) Biochemical changes during storage of sweet potato roots differing in dry matter content. Postharvest Biol Technol 24: 317-325.

5. Senanayake SA, Ranaweera KKDS, Gunaratne A, Bamunuarachchi A (2013) Effect of heat - moisture treatment conditions on swelling power and water soluble index of different cultivars of sweet potato (Ipomea batatas (L). Lam) starch. Volume 2013: 502457.

6. Kawaljit SS, Narpinder S (2007) Some properties of corn starches II: Physicochemical,gelatinization, retrogradation, pasting and gel textural properties. Food Chemistry 101: 1499-1507. 